\title{
The Use of Traditional Medicine in the Implementation of Quaternary Prevention From the Perspective of Experts in Traditional Medicine
}

\author{
Mohammad Hossain Mehrolhassani \\ Kerman University of Medical Sciences \\ Leila Vali \\ Kerman University of Medical Sciences \\ Yuosef Shaabani \\ Kerman University of Medical Sciences
}

Rahil GhorbaniNia ( $\nabla$ r.ghorbani6790@gmail.com )

Kerman University of Medical Sciences https://orcid.org/0000-0002-3153-0544

\section{Research}

Keywords: Quaternary prevention, Traditional medicine, Delivery of Health Care, Qualitative study

Posted Date: June 3rd, 2021

DOl: https://doi.org/10.21203/rs.3.rs-570632/v1

License: (1) This work is licensed under a Creative Commons Attribution 4.0 International License. Read Full License 


\section{Abstract}

Background: Traditional medicine includes a variety of disease treatments or prevention methods based on knowledge, skills, and practice that are rooted in indigenous beliefs and experiences. It also has a health-oriented and holistic view and considers measures following the characteristics of each individual. Patient harm can be prevented by using Traditional medicine and limiting the use of ineffective and harmful methods.

Methods: This qualitative study with the phenomenological approach was carried out with the participation of 12 individuals who were selected using purposeful sampling and snowball sampling methods among the faculty members of the Faculty of Traditional Medicine of Kerman University of Medical Sciences between May and June 2019. The data collected through semi-structured interviews based on the research objectives, review of texts. Data analysis performed using the content analysis method in MaxQDA software.

Results: Data analysis provided six main categories of the necessity of services, patient benefit, complications, prevention, rules and regulations, the financial burden.

Conclusion: Quaternary prevention is a concept derived from Traditional medicine. Health care providers must protect their clients from the harms and costs of unnecessary diagnostic, therapeutic, and preventive measures. By employing Traditional Medicine specialists and integrating the Traditional Medicine specialist program in the family doctor program, attending general and specialized hospitals, integrated medicine could use, and the harm to the patient could minimize.

Trial registration: IR.KMU.REC.1400.032 date: 1400/1/17 (6 April 2021)

\section{Background:}

In 1995, Jamoulle and Roland proposed the term quaternary prevention [1]. The purpose of quaternary prevention is not to prevent diseases but to prevent harm to patients caused by unnecessary medical services [2]. The goal of quaternary prevention is to protect patients by preventing avoidable harm by the ethical code of nonmaleficence. In other words, quaternary prevention means protecting consumers from unexpected harm when they need health services [3].

The goals of quaternary prevention could divide into three categories; 1 ) reducing exposure to the health care delivery system such as care of pregnant women by midwives instead of family doctors, 2) preventing harm caused by medical services such as not prescribing antibiotics in viral sinusitis, and 3 ) reducing the rate of exposure to medical care delivery system, such as avoiding unnecessary hospitalization of the patient [4]. Jamoulle and Roland's prevention framework emphasizes the need for other aspects of prevention by the interactions between patients (as consumers of health services) and physicians (as providers of health services), [5]. 
Traditional medicine is referred to a set of native or adventitious health care actions outside the mainstream health care system of any country [6]. Traditional medicine is according to knowledge, skills, and functions rooted in indigenous beliefs and experiences of different cultures [7]. This medicine includes types of disease treatments and prevention methods, that method and effectiveness of which is distinct from conventional or biological medicine. In this method, the patient is getting cured as a whole without emphasizing a particular disorder or disease [8]. Traditional medicine methods in terms of application have a variable range in different countries $[9,10]$ used for prevention, treatment, and health promotion $[7,11]$. Traditional medicine is not based on therapies, repetitions, and senses but on the principles of providing suitable ground. These principles include using the healing power of nature, finding the root cause of the disease, the rule of nonmaleficence, holistic treatment of individual instead of disease processes, prevention, and the principle of a physician as the teacher [12].

Studies have shown that patients in the world are increasingly turning to Traditional medicine [13-15]. The World Health Organization (WHO) has identified research and integration of Traditional medicine as one of its global priorities for the next decade [16]. A recent study found that the rate of using Traditional medicine in Cambodia, Thailand, and Vietnam was 76.7\% [17]. Also, Traditional medicine is widely used in Malaysia (63.9\%) and Thailand (52.5\%) [18]. A systematic study showed that East Asian countries use Traditional medicine the most [19]. However, the popularity of Traditional medicine is not limited to East Asian countries [20]. In the United Kingdom, the United States, and Canada, people also use Traditional medicine [19]. The main reasons for most people to choose Traditional medicine include the desire to perform a specific method, its greater comprehensiveness, and its fewer side effects [21]. Studies also confirm that methods known as Traditional medicine seem to be not only efficient but also have great potential for savings. In Traditional medicine, physicians seek to strengthen the body's healing capacity and patients' self-care. Therefore, prescription drugs and laboratory tests are less common than the conventional medicine approach [22].

The satisfaction obtained from Traditional medicine methods has a great effect on patients and their families and encourages them to use this method. Although this method began in East Asian countries, its use is on the rise in Western countries due to its low cost compared to conventional therapies, the positive attitude of people towards biological products, and people's belief in the harmlessness of this method [23]. Traditional medicine has a health-oriented view on medicine (through the strengthening of nature). It also believes that an integrated intelligent system controls the whole body and uses various existing systems such as the autonomic system, hormones, cardiovascular system, etc., to manage this control and harmony. The second characteristic of Traditional Iranian medicine is that each human being has unique physical, physiological and psychological characteristics, considering the necessary measures for each individual following these characteristics. In this view, while paying attention to the organ, it tries to treat the patient and not just the disease [24].

Analyzing people's benefits from Traditional medicine services is the first step in planning to expand the use of Traditional medicine methods and limit the use of ineffective and harmful methods. A valid data on these benefits can provide useful information on the overall rate of Traditional medicine use in the 
community. It can also help us to obtain a clear picture of the community's demand for these services, the way people act to find the answer to this demand, and the way the service delivery system responds to the community's demand. Proper analysis of this information can be a great help for policy makers, managers and providers of Traditional medicine services [25]. Talking about Traditional medicine always involves a wide range of reactions, from an extreme tendency to an unconscious and unreasonable denial. However, we are witnessing the growing spread of this medicine in society. Factors such as lack of response to treatment in conventional medicine, coordination of Traditional medical treatments with the nature of the patient, low cost, and simplicity of treatment are among the reasons for patients' tendency towards this medicine. Therefore, scientific, logical, and correct application of Traditional medicine can be effective in preventing its misuse and misunderstanding [26].

In 2016, the Ministry of Health and Medical Education, with the establishment of Iranian-Islamic Traditional medicine deputy and the faculties of Traditional medicine, opened the gates for education, research, and offering Traditional medical services. To preserve and ensure the health of the community, Traditional medicine has to use alongside conventional medicine. To increase the efficiency of measures and to have a direct and closer relationship with the faculties of Iranian medicine and their graduates, the offices of Iranian medicine established in the universities of medical sciences. Today, the role of physicians has been influenced by conventional medicine and, contrary to medical principles, these physicians have become highly dependent on modern medicine that results in many unnecessary services and high costs established for individuals and patients. Modern medicine should be in the service of Traditional medicine, but in reality, the opposite happens in the provision of services in service centers. In other words, Traditional medicine has diminished in society, and most physicians have become overwhelmed by the overuse of modern technology and equipment to provide treatment and services. Therefore, this study was conducted to investigate the possibility of using Traditional medicine in the implementation of quaternary prevention in the health system.

\section{Methods:}

Study design, site, and participants

It is a qualitative study with a phenomenological approach that was carried out between May and June 2019. The research environment in this study was the Faculty of Traditional Medicine of Kerman University of Medical Sciences. The research community consisted of the faculty members of the Traditional Medicine Faculty, from whom 12 people were selected by purposeful sampling. The sampling in this study continued until data saturation was achieved and no new data was acquired from the interviews. Consequently, 12 individual interviews were conducted with faculty members of the Faculty of Traditional Medicine of Kerman University of Medical Sciences. The study inclusion criteria included having expertise in the field of Traditional medicine and also, to have time for the interview. Also, people who neither had the time nor desire to be interviewed were excluded from the study. The participants were asked to introduce others who have the inclusion criteria. 


\section{Data collection}

The data collection tool was a semi-structured interview. Guidance has devised the questions based on the research's objectives and a text review for conducting the interviews. The interviews were conducted with prior agreement with the participants about the time and location. First, four in-depth interviews were conducted so that we could gain a better understanding of the concept, design the interview guide questions and identify the points to be considered during the semi-structured interviews. The duration of each interview varied from 20 to 60 minutes depending on the condition and preference of the interviewee. The interviews were recorded with the permission of the participants and were then demodulated. Interviews began with a general question to help the respondents feel comfortable and freely express their thoughts and views. The place of the interview was agreed upon by each participant. To comply with ethical standards, individuals were included in the study with their consent without any compulsion. Ethical considerations such as confidentiality of information and opinions of the interviewees, the possibility of making the research results available to the stakeholders after the study, and explanation about the purpose of the research to the interviewees were preserved in this study. The participants could skip any question they were not willing to answer. To conduct the research, the researcher went to the participants' workplaces and interviewed them there. The participants were informed that they might be contacted again to complete the process. Moreover, they were told that if they wished, they could have the results of the study.

To increase the validity of the data and ensure its transferability, the researchers tried to clearly state the context and characteristics of the participants [27]. Also, the data were reviewed by the research team (peer check), and initial analysis was reviewed by several participants (member check)[28]. For the interviews, a guide to the study objectives was prepared. Also, to determine the validity and ensure the correctness of questions from the respondents' point of view, the questions were checked with an expert who was not part of the study and according to his opinion, necessary corrections were made to the questions. The interview questions were related to patient benefits, costs, complications, prevention, rules and regulations, and the need to provide services.

\section{Data processing and analysis}

The content analysis method was used to analyze the data. Qualitative content analysis is a specialized method in scientific data processing, which is used to determine whether certain words and concepts exist in the text to summarize, describe and interpret the data [29]. The content analysis method consists of 5 stages of data familiarization, identifying the thematic framework, indexing, drawing the table, and interpretation. This method consists of several distinct, interconnected, clear, and orderly steps that, by following a well-defined work procedure, make it possible to consider and work on ideas [30]. In this study, the data familiarization phase was done by implementing, reading, and listening to the recorded interviews. After this step, the implemented texts were coded and summarized. After coding the initial interviews and placing similar codes in certain classes, the initial thematic framework was formed. Then, the implemented text was indexed using the codes related to the themes and sub-themes of the 
conceptual framework. Where appropriate, parts of the data were encoded with one or more codes. The thematic framework was reviewed by repeating the data familiarization process based on the interviews and meetings that were held between researchers and interviewers. The extracted themes and subthemes were repeatedly revised during the analysis process. In order to view the entire data in a categorized manner, a table was drawn in which, each table row represented an interviewee with the appropriate code, and the table columns represented the themes. For the final analysis, the tables were put together in such a way that it would be possible to compare the views expressed by an interviewee in the form of main themes and sub-themes (by looking at the columns) and also to compare the views of different interviewees about each theme (by looking at the rows). At this stage, the concepts, contradictions, theories, and experiences were compared and the desired patterns and relationships were inferred. The participants were assured about the confidentiality of their information. The interviews' text was read several times to gain a general understanding of them. The initial codes were then extracted and merged. The codes were also classified based on their differences and similarities. All coding and classification steps were performed through MaxQDA-10 software.

\section{Results:}

Analysis of the interviews resulted in the extraction of 6 main themes and 24 sub-themes (Table 1 ). 
Table 1

The possibility of using Traditional medicine in the implementation of quaternary prevention from the perspective of experts at the Traditional Medicine Faculty of Kerman University of Medical Sciences

\begin{tabular}{|c|c|c|}
\hline No & Main category & Sub-category \\
\hline \multirow[t]{3}{*}{1} & \multirow{3}{*}{$\begin{array}{l}\text { Necessity of } \\
\text { services }\end{array}$} & Provide safety of services \\
\hline & & $\begin{array}{l}\text { Delivery of prescriptions to patients with the assurance of the correct } \\
\text { provision of herbal medicines }\end{array}$ \\
\hline & & Provide logical, scientific and correct services \\
\hline \multirow[t]{7}{*}{2} & \multirow{7}{*}{$\begin{array}{l}\text { Patient } \\
\text { benefits }\end{array}$} & Patient need for tests, treatments, processes \\
\hline & & Prevent excessive delivery of services and avoid patient harm \\
\hline & & Prevent excessive delivery of services to end-stage patients \\
\hline & & Prevent excessive delivery of services to elderly \\
\hline & & Patient demand \\
\hline & & Service effectiveness \\
\hline & & Use of clinical epidemiology \\
\hline 3 & Complications & $\begin{array}{l}\text { Complications and explanation of the advantages and disadvantages of } \\
\text { providing Traditional medicine services (cupping, consumption of medicinal } \\
\text { plants, massage therapy, etc.) }\end{array}$ \\
\hline 4 & Prevention & Measures to prevent disease relapse and lifestyle modification \\
\hline \multirow[t]{3}{*}{5} & \multirow{3}{*}{$\begin{array}{l}\text { Rules and } \\
\text { regulations }\end{array}$} & Deal with non-physician health care providers \\
\hline & & Generalization and weak implementation of rules and regulations \\
\hline & & Measures to deal with non-physicians in the field of Traditional medicine \\
\hline \multirow[t]{3}{*}{6} & \multirow{3}{*}{$\begin{array}{l}\text { Financial } \\
\text { burden }\end{array}$} & Patient cost \\
\hline & & Provide cheaper alternative services \\
\hline & & Costs imposed on the health system \\
\hline
\end{tabular}

To help improve and enhance the level of society's health, reduce unnecessary visits to medical centers and emergencies, increase public awareness about logical health services and prevent injury to patients, we need to rationalize the provision of Traditional medicine services along with conventional medicine. In this study six main themes including the necessity of service, patient benefit, complications, prevention, rules and regulations, and financial burden along with 24 sub-themes were derived from the data.

\section{Necessity of service:}


In many parts of the world, policymakers, health professionals, and people are still challenged with issues such as safety, effectiveness, quality, availability, preservation, and use of Traditional medicine. They must make decisions based on the quaternary prevention concepts regarding the best treatment with minimal side effects. Traditional medicine is still widely used in many countries and its use is increasing rapidly in other countries. At the same time, interest in Traditional medicine has grown among the medical community.

\section{Provide safety of the services}

Despite the effects of Traditional medicine on health care, little is known about the safety of Traditional medicine. Many physicians believe that this medicine at best is not approved and is unsafe or harmful at worst. The interviewees acknowledged that:

"One of the conditions that the World Health Organization has set for countries to practice their Traditional medicine is safety, which is cost-effectiveness, and so on. The logic behind Traditional medicine is its health-centeredness." (P: 1)

"WHO accepts six of our books and says that without a clinical trial, you can easily prescribe them because they have been prescribed for more than 1000 years and no specific issue has been reported... Another issue is that patient who comes for visiting frequently, or at shorter intervals because it is safer and we do not want to make a mistake in the treatment ". (P: 4)

"Look, it may have fewer side effects than modern medicine surgeries, but it's not safe. It is not as invasive as surgery... I think its risk is moderate; I mean it can have side effects, especially in leech therapy or cupping." (P: 5)

\section{Delivery of prescriptions to patients with the assurance of correct provision of herbal medicines}

Preparing medicines prescribed by a Traditional medicine specialist is generally a difficult task because firstly, there are only a few centers that provide medicinal plants, and secondly, there is a big difference between the existing centers in terms of the quality of manufacturing, preparing, keeping and prescribing them. The task of preparing a drug, which is sometimes a combination of several other drugs, takes a lot of time if done by a specialist, and if it is left to the patient, there is a possibility of many and even dangerous mistakes, which negatively influence the desired effect. Interviewees stated that:

"Look at the drugs we prescribe here. To make sure people get them from a safe place, we have a Traditional medicine pharmacy in our health center. Our pharmacy is under the supervision of the Food and Drug Administration, so everything that is presented is passed through our filter." (P: 3)

".... If patients get their medicine from outside the center, they may be harmed. We have no control over those suppliers. Usually, the pharmacies of the health center are under the supervision of a specialist. He is in charge of the medicines that we supply here. The medicine is not given to the patient by mistake. One of the problems is that we do not have a standardized delivery system. To solve the problems, 
different solutions have been predicted. For instance, the centers should have their herbal medicine supplier or the Traditional health centers should be able to produce medicinal drugs on their responsibility." (P: 5)

\section{Provide logical, scientific and correct services}

The scientific, logical, and correct provision of Traditional medicine can be effective in preventing its misuse and misunderstanding. Given that there is still no absolute method for treating diseases, it is necessary for all groups involved in health and wellbeing to work together away from prejudice to improve patient health and wellbeing. The interviewees in this regard stated:

"The Traditional medicine of each country is completely different because it is native to a certain region. The Traditional medicine services of each country should be integrated with the health system of that country and we should achieve integrative medicine. Integrative medicine states that patients should be viewed as a whole, and we should use everything we have such as Traditional medicine, nutrition, conventional medicine, etc, and see which one of these can benefit the patient. The only way is that a Traditional medicine specialist and a conventional medicine physician would be linked to each other. We should be coordinated and work as a team." (P: 6)

"They should hold series of training and workshops in this field, and in fact, explain these levels of service delivery, so that physicians would get familiarized with it and get a better mentality about it. When they enter a phase, at least they have some information about it. It can lead to good and constructive interdisciplinary interaction." (P: 3)

"One way is the existence of Traditional health centers. Because these centers are under the supervision of $s$ Traditional medicine specialist and these are, in fact, all the facilities that a person can ask for. Another thing that we do not have in the country right now is to enter the hospitals. Entering the hospital is a good thing, and we should participate in new medical consultations ... Another issue is the tariff. We have problems with insurance when it comes to tariffs" $(P: 5)$.

"To provide services, we need to prepare an academic context for it. Then, there must be a high level of political commitment at various political levels. Emphasis should be placed on safety and education and being educated and research-oriented. Services should have a scientific basis. We have the same objectives as the WHO; I mean, most of it is knowledge and being safe." (P: 1)

\section{Patient benefit}

In quaternary prevention, any harm to the patient should be prevented. Treatment is acceptable if it does not cause any harm to the patient and the patient benefits from it the most. Using the recommendations of Traditional medicine, healthy eating habits and a healthy lifestyle are taught to people for their benefit. Health is everyone's right and no one should be sick. By providing correct, timely, and accurate services scientifically, we can improve people's health. 


\section{Patient need for tests, treatments, and processes}

The more time a physician spends on taking a patient history, and the more he or she determines the treatment based on the patient's needs and participation, the better treatment choices will be available for him/her. The basis of diagnosis in Traditional medicine is the diagnosis of temperament. Auxiliary tools in the diagnosis of Traditional medicine include pulse, face color, skin color, tongue, and body temperature. Ultrasound, MRI, and other assisting devices are sometimes used, but this does not mean that Traditional medicine diagnosis cannot be made without them. Diagnostic aids, whether laboratory or para-clinical, play a role in assisting diagnosis in Traditional medicine. The interviewees acknowledged that:

"In fact, it may be said that quaternary prevention wants to make the treatment effective. What is important in quaternary prevention is to know which patient benefits from what kind of treatment. In what way can this patient benefits the most seems to be very important in the quaternary prevention." (P: 1)

"Usually, the patients who come here have already received all the services offered by conventional medicine. They usually have the test results with them. But, if there is a test that patient needs to do, we will refer him. It is according to patient indications and clinical examinations that we decide whether we need these tests or not." (P: 3)

"The use of tests is very important in our diagnosis." (P: 4)

"It is not necessary for everyone. We refer the patient for a test if there is an indication for it even in conventional medicine. I do not impose any costs on the patient until I feel that it is necessary ... In the case of radiation, we should also consider the harm that comes with it along with other things. It is all about cost, time, money, transportation, and the stress that comes with it. That's why I do not prescribe any test until it is necessary." (P: 6)

\section{Prevent excessive delivery of services and avoid patient harm}

Health professionals can play an important role in reducing the harm of Traditional medicine treatments to patients. Providing and promoting people's health in the community is a goal that has been set for many years by senior managers of the health system to provide services in the furthest parts of the country. Health officials are required to use Traditional medicine and make the right decision by considering sufficient and accurate information. The physician is the servant of nature, and sometimes without the physician's intervention, people can be helped to live a healthy life by using the six essential principles of Traditional medicine. In this regard, the interviewees stated:

"We try to avoid patient harm in the training that we provide to our assistants so that the harm and complications would be minimal. Well, if our patient does not need any intervention, we try to prevent any intervention for him either in prescribing herbal medicines or in providing services such as medical practices." (P: 3) 
"Most of our work is preventive and lifestyle improvement. I mean, what has always happened during these years is that we have tried not to provide services that there is no indication for them ... During these years, this has been internalized in people because from the very beginning we tried not to provide unnecessary services." (P: 4)

"We have an interesting term that says the physician is the servant of nature. Well, it means that the physician must fully assess the condition of the body, patient history, recent clinical tests, and patient condition. It is often believed that the immune system of the body is intelligent and can solve many problems on its own. The physician's only job is to recognize this process and help it. Traditional medicine believes that sometimes, not intervening is the best intervention that the physician can do." ( $P$ : 6)

\section{Prevent excessive delivery of services to end-stage patients}

Physicians are responsible for patients. So, where they feel they cannot do anything, they should refer the patient. They should also have a scientific exchange with their colleagues. Cancer patients who are treated with conventional medicine often turn to Traditional medicine specialists to reduce the complications of the disease and its treatments, to create opportunities for a better quality of life, and to find a complete cure. The respondents in this regard stated:

"We do not tell our patients that we can do everything for them, or do not use conventional medicine anymore. When a patient comes to us, we always emphasize that he must be in touch with his specialist and should not stop taking his drugs. We emphasize that the patient should keep in touch with his oncologist. If we prescribe a drug, we make sure that the drug has no contra interactions with the patient's medications, and we tell the patient to inform his oncologist." (P: 3)

"We have a problem in modern medicine, which is the term end-stage. We say this because we think the patient is done, and there is nothing that can be done about it. But in Traditional medicine, we say we are the caretaker of nature. The physician is the caretaker of nature. We help the intelligent system that is the body to control the illness. Yes, you see the patient has cancer and constipation. By treating constipation and controlling the pain, we can help improve the quality of life of the patient and help him better spend the rest of his life. Surely, the better he lives, the longer he can live." (P: 12)

"At the end stage, Traditional medicine cannot do much. The end-stage patients have their conventional treatments, and we do not change those treatments, because there is a person who is under the supervision of a specialist and has some risk factors. The first thing we do for an end-stage patient is to modify the patient's lifestyle. The medicine that the patient is taking, which is often the chemotherapy medicine, may have many contra interactions with the drugs that we offer. So we consider the drugs and their contra interactions. In any actions that we do for the patient, we are very careful, and modifying the lifestyle is at the top of our action." (P: 5) 
"Desperate Patients come to us. We can affect their quality of life. ... We tell them if there is a particular person they want to go out with. I mean, we pay so much attention to their mental state." (P: 9)

"Every end-stage patient has a routine treatment; a palliative care. We ask them if there is something that we can do to increase their quality of life because, for the end-stage patient and the health system, the important thing is the quality of life. It means that they should live well as long as they are alive. We ask if there is a service that they think can help their quality of life, and we provide whatever they seek." (P: 1)

"We pay attention to the food arrangement and the work related to the lifestyle whatever it may be. We try to increase the patient's quality of life. The rest is not up to us, because we are not allowed to intervene with patient's treatment." (P: 6)

\section{Prevent excessive delivery of services to elderly}

Most referrals to Traditional medicine are related to middle-aged and elderly people. These people come to receive Traditional medicine services along with the services received from conventional medicine. Joint pain, back pain, and digestive problems are among the most common problems in the elderly referring to Traditional medicine centers. In this regard, the participants stated:

"Traditional medicine offers a series of measures to elderly people. These measures are aimed at improving the quality of life. Well, we aim to explain the six necessary principles to these patients. If we want to prescribe something, we will make sure that it is more related to nutrition." (P: 3 )

"In Traditional medicine, the temperament and physical condition are very important. For the elderly patients, increasing the strength is considered as the first step, and then, it is all about lifestyle and six principles. Then, if needed, we go for medicine or other things." (P: 11)

"Elderly patients, who happen to need a lot more, also have financial and mental problems. I have to pay a lot of attention to these issues. But if the medicine is needed, sometimes we have to prescribe it. ... If there is a need for referral, we will refer the patient." (P: 4)

"For the most part, Traditional medicine can help prevent and control chronic diseases. That means we try too hard not to intervene in acute illnesses. But on the contrary, in chronic illnesses like blood pressure, digestive problems, constipation, and things that bother the elderly, there are many referrals. These problems can be treated by lifestyle changes or a couple of drugs." (P: 6)

\section{Patient demand}

Sometimes, although there is evidence that some methods are ineffective, patients choose them because of the strong tendency that is rooted in their beliefs. The participants stated that:

"It depends on the ethics. If you want to work professionally, you should not listen to the patient and respond to his demand if the patient is asking for cupping and you know that it is harmful to him. So under any circumstances, you are not morally allowed to listen to him, and you have to justify it." (P: 1) 
"This is in people's culture. They think that if they perform the test, they will be ok. This is the exact opposite of what we say in Traditional medicine because the standard has the size and the test has suffered. In our view, he is a patient, but according to the test, he is a healthy person. In my opinion, some people have no indication, but for some people, we have to do it (with laughter). We resist as much as we can, but sometimes we see that it is no longer useful." (P: 2)

"Our health center has become known as an academic and specialized health center. Fortunately, those who come here have a basic knowledge of Traditional medicine. ... Our clients have the knowledge, and usually, when we prescribe something for them, they receive it very well and trust us." (P: 3)

".... It is not like I do my diagnosis based on the patient's demand. We are responsible and must be accountable, whether to the patient or our conscience. I do what I recognize, and I don't listen to patient's request." (P: 10)

"I do what the law, my conscience, and my knowledge say. Many of my colleagues may prescribe what the patients ask them to write. But I never do that. ... This is my opinion now. In Traditional medicine, this is the case, especially in the cases of cupping and manual measures. We allowed those who wanted the manual measures to have free visits, and we do not do it without a visit. It is because the specialist could see whether the patient has any indication or not." (P: 6)

\section{Service effectiveness}

Clients who ask for Traditional medicine services believe that, the effectiveness of this treatment method is much greater than conventional medicine. Normally, people who go to Traditional health centers have already tried conventional medicine, and finally, have developed a tendency towards Traditional medicine. The interviewees in this regard stated that:

"We, at the integrative medicine, say that patient needs a cheap, safe and affordable treatment. This cheap, safe, and effective treatment may not necessarily be in allopathic medicine. For example, at this stage, supplementary medicine can respond to the patient. The quaternary prevention wants to make the treatment effective." (P: 1)

"We can begin with a more limited drug until the physician gets a good understanding of the problem. That's why our visit is a bit longer. Because the physician has to think and see what the problem is. With fewer drugs, we can give more benefits to our patients. I think maybe this is more preferable than new medicine." (P: 2)

"The advice we give is more related to the prevention. We advise patients to prevent some diseases from occurring or delaying them ... We also have a screen test. A screening test is mandatory for some people, even if they do not have any complaints. I do this when I have doubt, and I may ask for a colonoscopy." $(P: 6)$

\section{Use of clinical epidemiology}


To perform quaternary prevention, in addition to moral commitment, the physician must have the necessary skills to use clinical epidemiology and evidence-based practice in his decision to prescribe diagnostic, therapeutic, and preventive measures to prevent patient harm. In this regard, the participants stated:

"We have to be very up-to-date, and this must be done by research. Now, there are lots of problems in Traditional medicine. The method works, but some things prevent the method to be effective. However, in some cases, you can see the result." (P: 8)

"One of the problems that we have is statistics. In the groups where you can see different temperaments. Now, maybe in a certain temperament, certain food is bad and in another temperament is good. The general result that comes from statistics concludes that it does not make sense. Then, this result will be reflected in the literature. But, maybe the initial sampling was not right, or inclusion criteria were wrong." $(P: 6)$

\section{Complications}

Quaternary prevention is a moral obligation in which health care providers protect their clients from harm and the costs of unnecessary diagnostic, therapeutic, and preventive measures. Based on the patient's history and indications, the services required by him/her should be determined to prevent him/her from physical and mental harm.

\section{Complications and explanation of the advantages and disadvantages of providing Traditional medicine services (cupping, consumption of medicinal plants, massage therapy, etc)}

Not all complementary and alternative medicine methods are safe, and many of these treatments and prescribed drugs have dangerous side effects, and some are fatal. According to the indication, each patient should be provided with the services he or she needs, and additional or unnecessary services should be avoided.

"In Traditional medicine, we have some manual actions that should have indications. Certainly, one of the deviations in marketing Traditional medicine is not seeing these indications and providing unnecessary services. Well, this is dangerous, and it is everywhere even, in Traditional medicine. Why? Because one of our problems in our university clinics is that the patient comes in and asks to be cupped, but we say you don't need it." (P: 1)

"Almost $100 \%$ of the times when we perform the manual measures for patients, they must sign a form that states they are aware of possible side effects. Sometimes, we prevent them from doing what they want to do." (P: 2)

"In prescribing herbal medicines or providing services such as manual measures like cupping, we first see whether the patient needs such services or not, and if there is no indication, they will not be prescribed." $(P: 3)$ 


\section{Prevention}

The quaternary prevention is based on the principle of "do not cause any harm first" attributed to Hippocrates. This principle is seen in Traditional medicine, in which the six essential principles are used by Traditional medicine specialists at the first step to improve the lifestyle and reduce therapeutic and pharmacological interventions.

\section{Measures to prevent disease relapse and lifestyle modification}

Traditional medicine methods are used along with conventional medicine to treat and restore health to sick people and prevent healthy people from getting sick. To reduce harm to patients, planning should be done to expand the use of Traditional medicine and limit the use of ineffective and harmful methods. In this regard, the interviewees acknowledged:

"Patient-physician relationship in Traditional medicine is very important. ... We recommend it to patients and even to those who are healthy. The logic behind Traditional medicine is to maintain health, prevent disease and reduce the costs of the health system." (P: 1)

"The follow-up is important in Traditional medicine. In Traditional medicine, we have a good follow-up, which means we do not leave the patient alone. In follow-up, lifestyle modification is emphasized, and if necessary, the medicine is changed like conventional medicine. If some actions are needed, they will be taken, and we will monitor the patient until full recovery." (P: 7)

"Our main advice is on lifestyle; all aspects of lifestyle. If these devices are observed in healthy people and even in sick people, whose condition may change due to circumstances, many diseases do not occur in the first place, and if they do occur, they can be solved very easily with lifestyle change. They can be controlled." (P: 6)

\section{Rules and regulations}

Promoting quaternary prevention can significantly contribute to the greater compliance of the health care system with the constitution. By evaluating the status of Traditional medicine and the attitude of patients and physicians towards its sub-branches, it is possible to develop regulated health care strategies and policies. With these rules and regulations, the side effects of treatments are reduced and their beneficial effects are maximized.

\section{Deal with non-physician health care providers}

In recent years, laws have been put in place to ban the provision of Traditional medicine by nonphysicians and non-specialists. Receiving Traditional medicine services from non-specialists and unreliable people can have many consequences because these people are not familiar with the indications, harms, and therapeutic interactions and do not know the correct and useful way of using Traditional medicine methods in different people. Unnecessary and incorrect provision of services can 
cause harm to the patient. Therefore, their activities should be prevented, and they should be dealt with decisively by law. The interviewees in this regard stated:

"He was not a doctor, but he was very assertive. He said, why don't you let us work?' I said because of paragraph 4 of the order. Paragraph 4 says that any medical intervention can be supervised by the Ministry of Health. Political commitment is the last level in the implementation of a therapeutic option, and yet it has not been defined in the health system. Without political commitment, it cannot be done at the highest level, and the opposite is true. Anyone who can penetrate those levels can divert the path." (P: 1)

"Our problem is mainly with those who want to get rich too quickly. Someone has received limited training and taken a workshop for 4 hours or 8 hours, and now, he thinks he can play with people's life. That's why I think this should be taken seriously. Well, someone is interested to work in this field, then training workshops should be available for him, but the scope of his action should be specified, and his service should be strongly supervised." (P: 2)

"Currently, there is an office in the deputy director of treatment called the Office of Excellence in Iranian Medicine, and the number of Iranian medicine experts works there as supervisors. There have been cases of unauthorized service delivery and some harm to patients. The centers that provided such services have been closed. There is a decisive legal action, and the deputy director of treatment supervises them." (P: 3)

"In our country, the tragedy is that we do not have regulations for non-physicians. Physicians have regulations, and if they mistreat patients, they will go to court and pay fines. ... My suggestion is that rules and regulations should also be put in place for non-physicians. They should follow the example of countries like China and India, where they too have complementary medicine, and non-physicians are being monitored." (P: 5)

"Non-physicians are by no means legally allowed to visit, prescribe and treat patients, they are not allowed at all unless they are under the supervision of physicians ... But supervision is the responsibility of deputy of treatment that only has some staffs who just do that." (P: 6)

\section{Generalization and weak implementation of laws and regulations}

In the rules and regulations related to the development and use of Traditional medicine, there are general terms related to license and promotion of Traditional medicine. In order to eliminate the executive weaknesses and legal gaps, effective laws and even judicial interventions must be put in place.

"Let's hold a workshop for everyone and give them a certificate then there will be no supervision after all. However, you see there is the supervision of the deputy of treatment conducts the supervision and condemns some people, and then you see them that go somewhere else and start working again. ... There are problems that we always have because the law is not enforced properly." (P: 2) 
"I wish it was legal..., the office of Iranian medicine at the deputy of treatment and the university is pursuing this goal ... Some people go to the mosque and visit the people. They do not charge any money for visiting but prescribe expensive drugs and sell them to people. This way that they make many times more money. Unfortunately, their number has increased, and people do not know this issue." (P: 4)

"It's good to be legalized..., making sure that they don't go somewhere else and continue to work. Now, it is all about monitoring laws. When they are found, at least they will be dealt with. Because now, they find them at home, and since there is no supervision, they do nothing to them. They go from this home to the next. I think they should make some policies." (P: 5)

\section{Measures to deal with non-physicians in the field of Traditional medicine}

About non-physicians, we face two groups of people. First, the people who have been acquainted with the science of Traditional medicine from their fathers and their knowledge have been passed down from generation to generation. These people are familiar with the indications, drugs, and therapeutic interactions empirically. They also are valuable assets of Traditional medicine and should be used for training and proper use of Traditional medicine methods. A second group is a group of enthusiasts and people with some cross-sectional knowledge who are familiar with only part of Traditional medicine with limited indications. The scope of action should be set for this group of people.

"Different groups are part of the Ministry of Health's programs, particularly the apothecary. I would like to inform you that training for different groups has been defined by the Ministry of Health. But for the general public, we had several meetings with different goals." (P: 1)

"There are some people who are working in the area of folk medicine, which means common medicine. We have to use their experiences, take away those things that are useful, and do research on them, and put aside those things that may be wrong." (P: 12)

"... Everyone is taking courses; courses are being held, and we do not have control over the courses. You cannot stop them because people are interested in them without knowing their limits. They must teach them their limit in this area so that this field can advance. We should have enforcement laws in this area, which we do not have right now." (P: 5)

\section{Financial burden}

Despite the critical and extreme tendencies towards Traditional medicine, one of the reasons for its expansion is its low cost compared to conventional medical treatments. In quaternary prevention, emphasis is placed on reducing costs while maintaining quality. Traditional medicine, in terms of quality, safety, and effectiveness, helps to achieve the goal of access to health care for all people. Herbal remedies, Traditional therapies, and Traditional healers are the primary and sometimes the only source of health care for millions of people. This type of care is close to where people live and is accessible and affordable for them. 


\section{Patient cost}

Physicians should always consider how to treat patients without harming them physically, mentally, or financially. However, Traditional medicine treatments are not necessarily cheap. To be fair, it makes sense to have insurance cover for Traditional medicine services. The respondents in this regard stated:

"The logic (emphasis) behind Traditional medicine is to reduce the cost of treatment for the patient." (P: 1)

"Depending on how long the person should take the medicine, it is very different. One should take the treatment for two months, which may be cost about 100 tomans. But usually, the first prescription is at least 30 tomans. However, if it is for particular goals like increasing the strength, only the medicine costs about 15-20 Tomans." (P: 2)

"Unfortunately, Traditional medicine services are not covered by insurance. We have tried very hard to cover it, and these efforts are still going on, but unfortunately, this has not been done yet. Because it is not covered by insurance, the treatment cost is high. When prescribing medicine to a patient, always our concern is that we should only prescribe it until the patient needs this medicine. We are careful not to put financial pressure on the patient, and we try not to prescribe anything unless the patient needs it." (P: 3$)$

"It's different. Unfortunately, the major problem we have is that we are not yet covered by insurance, so our service usually costs the patient some money." (P: 6)

"Our drugs are not covered by insurance. Well, when it is not insured, its cost is high, and that in itself reduces the number of people who are interested in this method. They say that we are spending money on conventional medicine, what is the point of doing it here again?" (P: 5)

\section{Provide cheaper alternative services}

If there are alternative therapies that fit the patients' indication and financial capacity, they will be used to reduce economic pressure on patients. The interviewees in this regard stated:

"When a patient comes in, we give him a piece of paper and tell him to do this, do not do that, eat this, do not eat that... It depends on the individual. If he cooperates with us, the cost of his treatment will be reduced. (P: 2)

"In Traditional medicine, there are many alternatives. Maybe when we prescribe combined drugs for the patient, its costs are high. However, he may reach the same result with the single drug or the lighter drug. In such cases, it may take a longer time for the patient, but it costs is less." (P: 3)

"It depends on the patient. If the patient can tolerate it, we will choose the less aggressive way. Of course, it is not like coming from the end to the beginning."

\section{Costs imposed on the health system}


In addition to reducing the costs for the patient, using Traditional medicine will reduce unnecessary referrals to the health system and prevent unnecessary services. Many of their problems can be controlled if people use the six necessary principles with the opinion of doctors and specialists in this field, and improve their lifestyle. So, the need to perform unnecessary tests and invasive procedures is reduced. Therefore, the costs of the health system will also be reduced. The interviewees believed that:

"The logic behind Traditional medicine is that you should go forward with a preventive approach even in the treatment of disease. Not only in healthy people but also in patients, in Traditional medicine, we first see the main reasons that have caused the disease. Now, you can see which diseases are costing the health system more. If we leave aside the accidents, the rest are all chronic diseases or the so-called noncommunicable diseases. (P: 1)

"Now, prevention is one thing, and therapeutic intervention is another thing, which is, in fact, para-clinical interventions that have a financial burden for both the patient and the health system. Often, if prevention is observed, para-clinical interventions may not be needed. There are also many common diseases which are mild to moderate cases do not need treatment at all; only lifestyle changes." (P: 6)

\section{Discussion:}

In the present study, the feasibility of using Traditional medicine in the running of quaternary prevention from the perspective of Traditional medicine experts was investigated. Participants believed that during the running of Traditional medicine, the need to provide services is considered. In this view, delivering prescriptions to patients should be with the assurance of the correct provision of herbal medicines, and also the logical, scientific, and right provision of services are effective in ensuring the safety of services. Mozaffarpour et al., in a study, stated that a physician is more useful at the time of health because he tries to maintain health by providing the necessary instructions. This perspective is also effective in treatment and diagnosis. According to Traditional medicine experts, even in treating patients, before using the drug and interventions (massage, surgery, cupping, etc), it is necessary to ask about the patient's lifestyle and correct it as much as possible [31]. In Traditional medicine, each person is considered to have unique physical, physiological and psychological characteristics, and following these characteristics, the necessary measures are considered [32]. In a study, Taghipour et al. stated that the effectiveness of complementary medicine treatments is based on the experiences of Traditional medicine physicians and exiting resources rather than laboratory and clinical studies. However, the World Health Organization (WHO) has adopted a strategy for countries around the world to pay more scientific and practical attention to Traditional medicine to determine and ensure the safety, efficiency, and quality of Traditional medicine products and treatments and facilitating its entry into the field of conventional medicine [33]. Medical practice should be performed according to known standards at an acceptable level of professional skills and competence. Complementary medicine centers should avoid actions that harm the patient [34]. Concerning Traditional medicine, Razi, in his moral advice in the book "Al-Hawi" has emphasized the correct use of drugs and therapeutic methods for treatment [35]. Given that people avoid negative experiences and apply useful experiences to maintain and increase their health and well-being, 
Traditional medicine seems to have had at least satisfactory results for people in need of essential services, and this has led to its preservation and ability to be passed on to future generations.

In the present study, the interviewees acknowledged that the patient's benefit is considered and preserved in Traditional medicine. They stated that it is done by determining the patient's need for tests, treatments, and processes, preventing the delivery of excessive services to the patient, preventing any harm to the patient, preventing the delivery of excessive services to end-stage people, preventing the delivery of excessive services to elderly, patient demand, service effectiveness, and use of clinical epidemiology. The use of Traditional medicine is probably less dependent on advanced and even simple diagnostic tests [36]. Of course, all necessary tests and imaging procedures should be requested regardless of the Traditional medicine approach [37]. Providing useful services (principle of usefulness), preventing harm (principle of nonmaleficence), justice (principle of justice), and respect for human dignity (principle of autonomy) are the ethical principles of Traditional medicine, which have been based on the priority of patient's health, and are accepted by most medical communities in the world [38]. Specialists and staff of Traditional medicine are required to observe the principles of professional behavior and ethics. Patient comfort and well-being is a general principle in medical ethics and behavior. In the commitments of Traditional medicine centers, it must be assured that the health and interests of patient must always come first [33]. In a study in Canada, Esmail examined the experience of people using Traditional medicine services and found that, unlike conventional medical treatments, Traditional medicine treatments have real and immediate effects, and Traditional medicine is superior to conventional medicine [39]. In the study of Shams Ardakani et al., people believed that the satisfactory results obtained from the methods of Traditional medicine had a significant effect on encouraging patients and their families to use Traditional medicine [40]. However, in parallel with the development of Traditional medicine services, Traditional medicine centers must also gather sufficient demographic and clinical information needed to accurately diagnose the disease and provide effective treatment [41]. Regarding Traditional medicine Razi in his treatment recommendations considers two important principles in medical ethics, which include beneficence and nonmaleficence [35]. To prevent harm to the patient and to maintain and promote his health, the providers of Traditional medicine services should provide services based on the patient's indications and the need for those services to prevent harm to the patient. Traditional medicine in collaboration with conventional medicine in the form of combined medicine will have better effectiveness and efficiency. The patient can benefit from either of them separately or in combination, depending on his condition and illness, to prevent unnecessary services and protect the patient's interests.

In the present study, the experts acknowledged that any treatment, including Traditional medicine treatment, has side effects. In this regard, they stated that by determining the complications and explaining the advantages and disadvantages of Traditional medicine services (cupping, consumption of medicinal plants, massage therapy, etc.) to the patient before performing any service, the patient would be able to choose the service with informed consent and knowledge about all the possible side effects as well as advantages and disadvantages of the service. The client charter has been communicated to various medical centers, including hospitals, pharmacies, and medical diagnostic laboratories. Proper 
receipt of services, receipt of information in a desirable and sufficient amount, the right to freely choose and decide about the service, respect for the privacy of clients and the principle of confidentiality and trust, and access to an efficient system for handling complaints and suggestions are the most important points of this charter [42]. In a study, Shams Ardakani et al. stated that one of the reasons for people to turn to Traditional medicine treatments is that they view them as harmless and reliable methods [40]. Conventional medicine and the public believe that Traditional medicine cannot cure many diseases with a certain severity. Traditional medicine, like conventional medicine, is effective in a small number of diseases, up to a certain level, so no exaggeration should be made about the therapeutic effects of Traditional medicine, and in fact, its specific limitations should be considered. To prevent complications in patients, service providers in Traditional medicine should consider factors such as physical and mental condition, age, habits, environmental conditions, occupation, type of disease, and location of the injury, and also avoid providing services if the person does not meet the requirements.

One of the results of the present study was the interviewees' acknowledgment of the prevention. In principle, Traditional medicine tries to prevent disease recurrence and make lifestyle modifications. The attitude of Traditional medicine is first on prevention and then on therapeutic measures [36]. Regarding Traditional medicine, Razi in his book "Al-Mansouri Fi Al-Tib" talks about maintaining health [35].

Traditional medicine seeks to keep a person in the best possible condition. One of these efforts is to give instructions and recommendations. One of these instructions is the six essential principles for maintaining health, which is one of the most valuable topics in ancient medicine [43]. Observance of these principles, which includes important points about the weather, food, movement and stillness, sleep and wakefulness, retention, vomiting, and mental illness, maintains health, and adjusting and modifying these six items is a way to treat diseases [44]. By practicing them, people can put themselves at the desired level of health. Research in Singapore shows that most people use Traditional medicine to stay healthy, and only $28 \%$ of them use it to treat disease [45]. Another study in South Korea showed that the use of Traditional medicine is very common, and the main reason for their use is to maintain health and prevent disease [46]. According to the results of Shams Ardakani et al., the study by increasing public awareness about Traditional medicine, in addition to therapeutic purposes, we maintain health [40]. According to the six essential principles of Traditional medicine, and lifestyle modification, people do not suffer from chronic diseases, which after that it is very difficult to return to their pre-disease state and achieve complete recovery. This issue shows that Traditional medicine pays attention to reducing the patient's harm caused by the disease, which is the logic behind quaternary prevention.

Interviewees also referred to the code of rules and regulations regarding Traditional medicine. In this regard, they stated that decisive action should be taken to deal with non-physician providers of services. Also, the generalization and executive weakness of the laws and regulations along with measures to deal with non-physicians in the field of Traditional medicine should be considered. In a study, Aghayani Chavoshi stated that regarding Traditional medicine, Razi has referred to physician fraudsters or nonphysicians as a great danger that in addition to threatening the lives of sick and disabled patients, targets the sanctity and respect of medicine. Therefore, a serious confrontation with such an issue is necessary [35]. In another study, Taghipour et al. stated that to preserve Traditional medicine, it is necessary to pay 
attention to its legal aspects from the perspective of patients, physicians, public and governmental institutions. Traditional medicine needs relevant and specific laws for its application and acceptable defense in legal communities. These laws should include physicians, patients, non-physicians such as apothecary, experimentalists, and herbalists, as well as classical medicine, the medical system, forensic medicine, and courts. The process of dealing with errors and omissions, and should be specified and the type of punishment should be defined. Responsible bodies should be introduced to provide the necessary documents and training. According to the specific diagnostic and therapeutic approaches of Traditional medicine and the type of clients, the Charter of Patients' Rights appropriate to these services and disciplines should also be amended or developed [33]. All treatment-related practices, especially manual therapies, which in Traditional medicine are known as healing practices, including cupping, purging, leeching, massage, cleansing, and purification should require the patient's informed consent [47]. According to the Islamic Penal Code, one of the most important pillars of treatment is patient consent [48]. Traditional medicine centers must carry out their actions by the authorized scientific instructions and valid scientific sources of Traditional medicine. Also, any carelessness or mistakes that lead to bodily injury or harm to others should be avoided regardless of their practical outcomes [49]. Since there is not enough scientific evidence for the efficiency and effectiveness of Traditional medicine methods, and also since the authorities for handling complaints about this medicine have not been defined and determined, the process of dealing with legal and ethical aspects of Traditional medicine has been facing many challenges. For this purpose, it seems that by revising the laws, defining practical regulations, and determining acceptable scientific resources, the centers authorized to provide Traditional medicine services can address these problems, eliminate these legal shortcomings and continue working according to regulations.

Finally, the participants acknowledged that the financial burden should be considered by the providers of Traditional medicine services. In this regard, the patient's cost, providing cheaper alternative services, and the costs imposed on the health system were mentioned by the participants. In Davati et al.'s study, the majority of samples believed that Traditional medicine costs the patient less than conventional medicine [50]. One of the main reasons why the World Health Organization has focused on the development and promotion of Traditional medicine in developing and low-income countries is its low cost compared to conventional medicine [51]. If there is an effective and cheaper approach in the diagnosis and treatment of the patient in Traditional medicine, the health centers should be obliged to refer the patient to receive related services [33]. In any country, including Iran, if the use of Traditional medicine is not associated with para-clinical tests, it can greatly help to reduce its costs [51]. Regarding the foundations of Traditional medicine, Razi refers to the principle of trustworthiness in physicians among the emphasized moral codes [35]. In this regard, although Traditional medicine can be effective in reducing the cost of patients and the health system, the concerns of the medical community and members of the public must also be considered. To develop and expand Traditional medicine, it seems that more principles such as culture building, clinical trials, monitoring the activities of centers and individuals providing Traditional medicine services, and preventing profiteering that can endanger people's health should be considered. 


\section{Conclusion:}

Quaternary prevention is a concept derived from Traditional medicine. This concept is rooted in an ancient principle in medicine, which states: "nonmaleficence is the most important principle." In this ethical commitment, health care providers protect their clients from harm and the costs of unnecessary diagnostic, therapeutic, and preventive measures. Paying attention to this level of prevention will have a significant impact on the costs of the health system by preventing the delivery of unnecessary services. These costs can be used to provide services to healthy people in health centers, and to promote the health and lifestyle of people. Also, because Traditional medicine specialists are not employed in the Iranian health system, by integrating the Traditional medicine specialist program in the family physician program and attending general and specialized hospitals, we can use combined medicine and minimize patient harm.

\section{Declarations:}

\section{Ethics approval and consent to participate}

The ethical considerations observed in this research included obtaining informed consents from the participants before their participation in the research and recording the interviews, not listing the names of the participants in the transcribed texts, and observing the principle of confidentiality (ethical code: No. IR.KMU.REC.1400.032). Receiving informed consent in writing in order to participate in the interview, observing anonymity and secrecy in recording the interviews, and assuring the participants of the confidentiality of their information and the right to participate in or leave the study were some of the moral principles of the study. The participants could skip any question they were not willing to answer. In order to conduct the research, the researcher went to the participants' workplace and interviewed them there. The participants were informed that they might be contacted again to complete the process. Moreover, they were told that if they wished, they could have the results of the study.

\section{Consent for publication}

Not applicable. The manuscript does not include details, images, or videos relating to an individual person.

\section{Availability of data and materials}

All relevant data are presented in this paper. The datasets generated and/or analyzed during the current study are not publicly available because the study uses primary data of interviews with participants.

\section{Competing interests}

All authors declare no competing interest.

\section{Funding}


This research did not receive any specific grant from funding agencies in the public, commercial, or notfor-profit sectors.

\section{Authors' contributions}

$M M H, L V, Y$ Sh and RGh contributed conceptualizing the study, drafting the manuscript and finalization. $\mathrm{M} \mathrm{MH}, \mathrm{LV}$ and RGh contributed in data analyses and results write up. LV, RGh, M MH thoroughly reviewed the manuscript and contributed substantially for necessary revision. LV and RGh final reviewed the manuscript and prepared for submission. The authors read and approved the final manuscript.

\section{Acknowledgements}

The authors wish to thank all the people who helped them in conducting this study. This study is the product of the dissertation in Health Service Management numbered 30208 in Kerman University of Medical Sciences.

\section{References:}

1. Pandve HT. Changing concept of disease prevention: From primordial to quaternary. Arch Med Health Sci 2014; 2: 254-6.

2. Jamoulle M. Quaternary prevention: first, do not harm. Rev Bras Med Fam Comunidade 2015; 10:1-3.

3. Kuehlein T, Sghedoni D, Visentin G, et al. Quaternary prevention: a task of the general practitioner. Prim Care. 2010; 10: 350-354.

4. Pezeshki MZ, Pezeshki S. Educating quaternary prevention (p4) in Iran for decreasing the harms and costs of unnecessary services in clinical medicine and public health. Payesh. 2013; 12(4): 329-33. [In Persian]

5. Martins C, Godycki-Cwirko M, Heleno B, Brodersen J. Quaternary prevention: reviewing the concept (Quaternary prevention aims to protect patients from medical harm). EUROPEAN JOURNAL OF GENERAL PRACTICE. 2018; 24(1): 106-111. https://doi.org/10.1080/13814788.2017.1422177

6. James PB, Wardle J, Steel A, Adams J.Traditional, complementary and alternativemedicine use in Sub-Saharan Africa: a systematic review. BMJ Glob Health 2018;31; 3(5): 1-18.

7. Agu JC, Hee-Jeon Y, Steel A, Adams J.A systematic review of Traditional, complementary and alternative medicine use among ethnic minority populations: a focus upon prevalence, drivers, integrative use, health outcomes, referrals and use of information sources. J Immigr Minor Health 2018; 31: 1-20.

8. Schimpff SC. Complementary medicine. Curr Opin Oncol 1997; 9(4): 327-31.

9. Tehrani Banihashemi SA, Asgharifard H, Haghdoust AA, Barghamadi M, Mohammad Hosseini N. The use of complementary/alternative medicine among the general population in Tehran, Iran. Payesh 2008; 7(4):355-362 (Persian). 
10. Harris PE, Cooper KL, Relton C, Thomas KJ.Prevalence of complementary and alternative medicine (CAM) use by the general population: a systematic review and update. Int J Clin Pract 2012; 66(10): 924-939.

11. National center for complementary and integrative health $(\mathrm{NIH})$. The use of Complementary and Alternative Medicine in the United States. 2017 cited 4 Feb; Available from: https://nccih.nih.gov.

12. Sarris J, Wardle J (Eds): Clinical Naturopathy: An Evidence Based Guide to Practice. Sydney: Elsevier; 2010.

13. Pearson H, Fleming T, Chhoun P, Tuot S, Brody C, Yi SY. Prevalence of and factors associated with utilization of herbal medicines among outpatients in primary health centers in Cambodia. Bmc Complementary and Alternative Medicine. 2018; 18: 114-123.

14. Wardle JL, Sibbritt DW, Adams J. The interface with naturopathy in rural primary health care: a survey of referral practices of general practitioners in rural and regional New South Wales, Australia. Bmc Complementary and Alternative Medicine. 2014; 14: 238-246.

15. Djuv A, Nilsen OG, Steinsbekk A. The co-use of conventional drugs and herbs among patients in Norwegian general practice: A cross-sectional study. BMC Complementary and Alternative Medicine. 2013; 13: 295-306.

16. World Health Organization (WHO). WHO Traditional Medicine Strategy 20142023. Geneva: WHO; 2013.

17. Peltzer K, Pengpid S, Puckpinyo A, Yi S, Anh Le V. The utilization of Traditional, complementary and alternative medicine for non-communicable diseases and mental disorders in health care patients in Cambodia, Thailand and Vietnam. BMC Complement Altern Med. 2016;16:92.

18. Jiaranaikoajorn T, Panthawangjul J. Use of alternative medicines among medical patients in Siriraj hospital. Siriraj Hos Gaz. 2002;54(10):603-10.

19. Harris PE, Cooper KL, Relton C, Thomas KJ. Prevalence of complementary and alternative medicine (CAM) use by the general population: a systematic review and update. Int $\mathrm{J}$ Clin Pract. 2012;66(10):924-39.

20. Berthold SM, Wong EC, Schell TL, Marshall GN, Elliott MN, Takeuchi D, et al. U.S. Cambodian refugees' use of complementary and alternative medicine for mental health problems. Psychiatr Serv. 2007;58(9):1212-8.

21. Wapf, V., Busato, A.: Patients' motives for choosing a physician: comparison between conventional and complementary medicine in Swiss primary care. BMC Complementary Altern Med 7(1), 41 (2007)

22. Kooreman P, Baars EW. Patients whose GP knows complementary medicine tend to have lower costs and live longer. European Journal of Health Economics. 2012;13(6):769-76.

23. National center for complementary and integrative health $(\mathrm{NIH})$. The use of Complementary and Alternative Medicine in the United States. 2017 cited 4 Feb; Available from: https://nccih.nih.gov.

24. Mozaffarpur S G A, Shirafkan H, Taghavi M, Mirzapor M. Investigating the difference between principals of Iranian Traditional medicine and modern medicine for providing a model for integrated 
medicine. IHJ. 2014; 1 (1) :10-15

URL: http://iahj.ir/article-1-32-fa.html

25. Tehrani Banihashemi S.A., Asgharifard H., Haghdoost A.A., Barghmadi M., Mohammadhosseini N.. The use of Complementary/Alternative Medicine among the general population in Tehran, Iran.

Payesh. 2008; 7 (4) :355-362

URL: http://payeshjournal.ir/article-1-644-fa.html

26. Mahrozadeh S, Lolavar A. Ethical considerations about complementary medicine. Iranian journal of Diabetes and Metabolism. 2007; 7(special issue): 85-90.

27. Speziale HS, Streubert HJ, Carpenter DR. Qualitative research in nursing: advancing the humanistic imperative. 5th ed. Philadelphia: Lippincott Williams \& Wilkins; 2011.

28. Zamani Alavijeh F, Niknami Sh, Mohamadi E, Montazeri A, Ahmadi F, Ghofranipour F, et al. [High risk behaviors among Iranian motorcyclists: a qualitative study]. Payesh. 2010; 9(3): 269-78.(Persian)

29. Beigzadeh A, Okhovati M, Mehrolhasani MH, Shokoohi M, Bazrafshan A. Challenges of the Bachelor Program of Health Services Management: A Qualitative Study. Journal of Health Management 2014; 17 (55): 29-42. [Persian]

30. Lacey A, Luff D. Qualitative Data Analysis.USA: The NIHR RDS for the East Midlands/Yorkshire \& the Humber; 2009.

31. Mozaffarpur S G A, Shirafkan H, Taghavi M, Mirzapor M. Investigating the difference between principals of Iranian Traditional medicine and modern medicine for providing a model for integrated medicine. IHJ. 2014; 1 (1) :10-15

URL: http://iahj.ir/article-1-32-fa.html

32. Avicenna. Al Qanun Fil Tibb (Arabic).Beirut: Al-Aalami Press, 2005; 2.

33. Taghipour A, Bahrami Taghanaki $\mathrm{H}$, Hosienzade $\mathrm{H}$, Noras $\mathrm{M}$. Ethical and legal challenges in complementary and alternative medicine. ijme. 2016; 9 (3) :23-31

URL: http://ijme.tums.ac.ir/article-1-5786-fa.html

34. Ernest E, Chohen MH. Informed consent in complementary and alternative medicine. Arch Intern Med 2001; 161(19):2288-92.

35. Aqayani Chavoshi A. A Reconsideration of the Principles of Medical Morality in Mohammad Ibn Zakariya Razi. Research Quarterly in Islamic Ethics 2017: 10(35): 65-78.

URL: http://akhlagh.maaref.ac.ir/article-1-348-fa.html

36. Ferdosi M, Soltani F, Molavi Taleghani Y. Status of Traditional Medicine in a Healthy Life Style: Review Study. jiitm. 2016; 7 (1):1-6

URL: http://jiitm.ir/article-1-659-fa.html

37. Adhami H, Sadraei Shamloo D. Molahezate akhlaghi dar tebe mokamel va jaigozin. Iran J Med Ethics Hist Med 2008; 1(2): 69-72. [In Persian]

38. Omidfar K. An overview of ethical issues in medical laboratories. Iran J Med Ethics Hist Med 2015; 8(4): 1-11. [In Persian] 
39. Esmail N. Complementary and alternative medicine in Canada: Trends in Use and Public Attitudes, 1997-2006. The Fraser Institute. 2007.

40. Shams Ardekani M, Ardeshir Rouhanifard S, Abedtash H. A Glance at Use and Prevalence of Complementary and Alternative Medicine in Other Countries Based on the Last Statistical Surveys. jiitm. 2011; 2 (1): 37-46.

41. Miller FG, Emanuel EJ, Rosenstein DL, Straus SE. Etical issues concerning research in complementary and alternative medicine. JAMA 2004; 291(5): 599-604.

42. Parsapour AR, Bagheri AR, Laryjany B. Maaannnshour hoghoughe bimar dar Iran. Iran J Med Ethics Hist Med 2010; 3(suppl3 ): 39-47. [In Persian]

43. Hedayati SH, Abdollahifard G, Rezaiian J. Setteye Zarorie of Naseri's health care; evidence of preventive medicine in Iranian Traditional medicine. Journal of Research on history of medicine 2014;3(1):43.

44. Siahpoosh MB. Six essential principles of Iranian Traditional medicine for maintaining health from the Quran's point of view. Quran and Medicine 2012; 1(4): 101-7.

45. Lim MK, Sadarangani P, Chan HL, Heng JY. Complementary and alternative medicine use in multiracial Singapore. Complement Ther Med 2005; 13(1):16-24.

46. Ock SM, Choi JY, Cha YS, Lee J, Chun MS, Huh CH, et al. The use of complementary and alternative medicine in a genereal population in South Korea: results from a national survey in 2006. J Korean Med Sci 2009; 24(1):1-6.

47. Avicenna. Qanun dar Teb, $6^{\text {th }}$ ed. Tehran: Soroush; 1370;vol 6: 366-78. [In Persian]

48. Taghaddosinejad F, Akhlaghi M, Yaghmaei A, Hojjati A. A survey of obtaining informed consent and acquit from admitted patients in Emam Khomeini hospital. Sci J Forenic Med 2008; 14(1): 12-17. [In Persian]

49. Salehi H. Masoliat madane nashi as farayande darman. Tehran: sina; 2013. [In Persian]

50. Davati A, Jafari F, Farahani Mashhadi S. Determining Knowledge and Attitude of Tehran Medical University Students on Traditional Medicine. Qom Univ Med Sci J 2011; 5 (S1): 13-18. [In Persian]. URL: http://journal.muq.ac.ir/article-1-621-fa.html

51. Nasrollahpour Shirvani SD, Mouodi S. Evidence -Based Policymaking in Health System and Its Achievements and Challenge in Iran. 1st ed. Babol: Babol University of Medical Sciences; 2013. [In Persian] URL: http://medolympiad.behdasht.gov.ir/uploads/book_2_162552.pdf 